\title{
Development and Evaluation of Gel Incorporated with Synthesized Silver Nanoparticle from Ocimum gratissimum for the Treatment of Acne Vulgaris
}

\section{S Lakshmana Prabu ${ }^{1 *}$, A Umamaheswari', S Rajakumar ${ }^{2}$, PL Bhuvaneswari ${ }^{1}$ and S Muthupetchi ${ }^{1}$}

${ }^{1}$ Department of Pharmaceutical Technology, University College of Engineering, Anna University, Bharathidasan Institute of Technology Campus, Tiruchirappalli, Tamil Nadu, India

${ }^{2}$ Department of Marine Biotechnology, Bharathidasan University, Tiruchirappalli, Tamil Nadu, India

Date of Receipt- 11/08/2017

Date of Revision- $01 / 09 / 2017$

Date of Acceptance- 10/09/2017

\section{Address for}

\section{Correspondence}

Department of Pharmaceutical

Technology, University

College of Engineering, Anna

University, Bharathidasan

Institute of Technology

Campus, Tiruchirappalli, India,

Tamil Nadu, India

Tel: $+91-9750550965$

E-mail: slaxmanvel@gmail.com

\section{ABSTRACT}

Acne vulgaris is one of the most prevalent skin diseases which affect almost $80 \%$ of adolescents in the world during their lifetime. Development of specific association between antibiotic and bacteria during repeated treatment develops antibiotic resistance. Medicinal and aromatic plants are widely used as medicine in ancient time. Treatment of acne has been considered as a major research area in pharmaceutical and personal cosmetic care industries. The aim of the present work was to evaluate the phytochemical composition of Ocimum gratissimum, green synthesis of silver nanoparticle and to develop herbal topical gel formulation to treat acne. Ocimum gratissimum is selected based on its antibacterial activity. Phytochemical analysis revealed phytoconstituents such as alkaloids, flavonoids, tannins and saponins are present in the extract. Silver nanaoparticle was synthesized using $1 \mathrm{mM}$ aqueous silver nitrate solution from the extracts of Ocimum gratissimum and formation of silver nanoparticle was confirmed by UV spectroscopy. The synthesized silver nanoparticles were stable, spherical shape with average particle size of $207.6 \mathrm{~nm}$ and the polydispersity index was found to be 0.256 . Synthesized silver nanoparticles was incorporated into gel base and evaluated for its physical properties such as $\mathrm{pH}$, viscosity, spreadability and antibacterial activity against Propionibacterium acne, Staphylococcus aureus and Escherichia coli. The results obtained in the developed formulation showed no lumps, had uniform color dispersion and were free from any fiber and particle. It was also observed to have easy washablity, good spreadability, $\mathrm{pH}$ was found to be 6.72 and 6.80 similar to $\mathrm{pH}$ of the skin. The antibacterial study of the developed formulation showed inhibitory activity against Propionibacterium acne, Staphylococcus aureus and Escherichia coli. Synthesized silver nanoparticle of Ocimum gratissimum showed higher activity than the extract. Hence, silver nanoparticle of Ocimum gratissiumum in aqueous gel-base can be used as an appropriate formulation for treatment of acne vulgaris.

Keywords: Ocimum gratissimum, Antiacne, Silver nanoparticle, Herbal gel formulation, Antibacterial activity, Phytoconstituents, Physical property

\section{INTRODUCTION}

Skin in the human being is the most susceptible part for entering various microorganisms into the body ${ }^{1}$.
Acne vulgaris is one of the most prevalent skin diseases which affect the young adults in the age group between 11 and 30 years. Among these age 
group $50.9 \%$ of women and $42.5 \%$ of men are susceptible to this acne vulgaris ${ }^{2,3}$. Hormonal influences, altered keratinization, inflammation and immune changes are the multiple factors involved in the formation of acne $e^{4,5}$. Acne vulgaris is a common dermatological condition associated with depression, anxiety and other psychological sequences ${ }^{3,6,7}$. Microorganisms such as Propionibacterium, Staphylococcus and Escherichia species are responsible for the development of acne ${ }^{8}$.

Continuous therapeutic application of antibiotic can develop an ineffectiveness of traditional antibiotic leading to resistance consequently resulting in incompetent effect against the particular disease. These developments of antibiotic resistances are due to the specific association developed between antibiotic and bacteria $^{9,10}$.

Phytomedicines from herbal plants are widely used as home remedy in ancient time to maintain normal health of human beings. As per World Health Organization (WHO) estimation, nearly $75-80 \%$ of population in the world utilizes medicinal plants for their primary health care ${ }^{11}$. Due to the development of antibiotic opposition and the availability of the large number of medicinal plants, made the scientist to focus the scientific exploration, develop and identify new antimicrobial agents from the natural source (medicinal plants) for therapeutic and prophylactic purpose. Traditional medicinal systems like Siddha, Ayurvedha and Unani are utilizing herbs for treating various diseases. India is a hub of medicinal plants; continuous scientific investigation of these indigenous drugs can provide cheaper and better therapeutic agent $^{12}$.

Skin consists of larger surface area which provides good accessibility and promising route to treat various diseases. Antimicrobial nanoparticle in topical formulation is considered effective for treating acne vulgaris. Among the various metallic nanoparticles, silver nanoparticle has been considered as most effective one against bacteria and virus ${ }^{11,13,14}$. The plant Ocimum gratissimum possesses several phytoconstituents and having many potential therapeutic activities in traditional system. Ocimum gratissimum, it has been used for various skin infections due to availability of abundant amount of volatile oil ${ }^{14-}$ ${ }^{17}$. Taking into consideration of the cost and easy availability of this medicinal plant, our present study was designed to explore systematically and analyze the phytoconstituents, synthesis nanoparticle by using plant extract then formulate topical gel containing silver nanoparticle and evaluate for its physicochemical properties and antibacterial activity.

\section{MATERIALS AND METHODS}

\section{Plant Materials}

The specimen for the proposed study was collected and confirmed by Dr. S. Soosairaj, Assistant Professor, Dept. of Botany, St. Joseph's College, Tiruchirappalli. Voucher specimens can be assessed as SJCBOT2196, Department of Botany, St. Joseph's College, Tiruchirappalli.

\section{Chemicals}

Chemicals were obtained from Rankem Laboratory Chemicals Pvt. Ltd., Haryana, India, Himedia Laboratories Pvt. Ltd, Mumbai, India and Loba Chemie, Mumbai, India.

\section{Preparation of Extract}

The leaves of Ocimum gratissimum were washed in water to remove the dust and foreign material from the surface then air dried under shade at room temperature. The air dried plant material was coarse powdered and subjected to methanol 
extraction using soxhlet apparatus by reflux for $24 \mathrm{~h}$ at $60^{\circ} \mathrm{C}^{18}$. A grey colored semisolid mass was obtained, dried under vacuum and kept in desiccators until use.

\section{Phytochemical Analysis}

Methanol extract was analyzed for its phytoconstituents such as saponins, anthraquinone glycosides, phyto steroids, tannins, flavonoids, carbohydrates, triterpenoids, polyphenol and alkaloids ${ }^{19,20}$.

\section{Synthesis of Nanoparticle}

In the single step green synthesis, $5 \mathrm{ml}$ of leaf extract was added to $95 \mathrm{ml}$ of $1 \mathrm{mM}$ aqueous silver nitrate solution and kept in the dark place at room temperature for $24 \mathrm{~h}$. Silver nanoparticles are formed by reduction of pure silver ions and it was monitored by measuring absorption of the reaction medium in the wavelength range of 300-700 nm using UV spectrophotometry. The synthesized silver nanoparticle (AgNP) was purified by centrifugation at $10000 \mathrm{rpm}$ for 15 min. The supernatant was transferred to a clean dry beaker for further settlement of particles and repeated centrifugation was carried using cooling microfuge to get dried, purified and characterized the $\mathrm{AgNPs}^{14}$.

\section{UV-Visible Spectral Analysis}

Silver nanoparticles were formed by reduction of silver ion; it was monitored by measuring the absorption spectra in the wavelength range of 300-700 nm using Shimadzu UV-1800 Spectrophotometer. The spectrum was recorded and the maximum absorption wavelength was determined ${ }^{14}$.

Particle Size Distribution and Polydispersity Index

The mean particle size of the silver nanoparticle was determined by Photon Correlation Spectroscopy (PCS) using a Zetasizer 3000
(Malvern Instruments, UK). This analytical result reveals the mean diameter of the particle at $25^{\circ} \mathrm{C}$, and at an angle of 90 degree $(n=10)$. The PCS analysis yields a mean diameter (z-average) as a light intensity-weighed size of bulk population and the polydispersity index as a measurement for the width of a particle size distribution ${ }^{14}$.

\section{Zeta Potential}

The zeta potential of the synthesized silver nanoparticle was measured by a Laser Doppler Anemometer connected with the Malvern zeta sizer instrument. A suitable amount of sample (50-100 $\mu \mathrm{L})$ was diluted with $5 \mathrm{~mL}$ of water $(0.45 \mu \mathrm{m})$ and injected in the electrophoretic cell of the instrument where a potential of $\pm 150 \mathrm{mV}$ was set. The zeta potential value was calculated by using Smoluchosky equation ${ }^{14}$.

Preparation of Topical Formulation

Topical gel formulations were prepared by cold mechanical method with defined quantity of carbopol-934 and HPMC polymer. The specified quantity (1 g) of polymers such as Carbopol 934 and HPMC were weighed separately and sprinkled slowly on surface of purified water ${ }^{21}$. To this defined quality of double distilled water was added with vigorous stirring and left overnight for dissolving the polymer. To the polymer solution, drug silver nanoparticles were added to the gel with continuous stirring. Required quantity of glycerol was added and mixed well by using magnetic stirrer. After complete dispersion, the $\mathrm{pH}$ of the gel was adjusted to neutral $\mathrm{pH} 7$ by using sodium hydroxide. Distilled water was added and made up to $100 \mathrm{~g}^{22,23}$. The herbal formulation composition is shown in (Table 1). Physicochemical Evaluation of Formulations ${ }^{22-24}$

Physical evaluation: Physical parameters such as color, appearance and consistency were 
checked visually.

pH: Aqueous solution (1\%) of the formulation was measured by using a calibrated digital $\mathrm{pH}$ meter at constant temperature.

Viscosity: Brookfield Viscometer (Brookfield Engineering Laboratories, USA) with spindle \#C 50-1 was used to measure the viscosity of the formulated topical gel at a speed of $50 \mathrm{rpm}$ in room temperature. Measurement of viscosity was done in triplicate.

Spreadability: Glass slides with standard dimension (length of $6.0 \mathrm{~cm}$ ) were taken. Topical gel formulation was placed on the one side of the glass slide and sandwiched with the help of another slide. Remove the adhering gel on the outer surface of the glass slides by wiping. Slides are fixed in a stand that only upper slide to slip off freely without any disturbance by force of weight $(20 \mathrm{~g})$ tied to it. Time taken for the movement of upper slide to the distance of 6.0 $\mathrm{cm}$ was measured. Measurement of spreadability was done in triplicate and calculated by using the following formula:

Spreadability $=($ Weight $\times$ Length $) /$ Time

Where, $S=$ Spreadability

$\mathrm{m}=$ Weight tied to the upper slide (20 g)

$1=$ Length of the glass $(6.0 \mathrm{~cm})$

$\mathrm{t}=$ Time taken in seconds

Preparation of inoculum: For evaluation of antibacterial activity, $24 \mathrm{~h}$ fresh culture of bacteria was suspended in sterile water to obtain a uniform suspension of microorganism.

Determination of zone of inhibition: Antibacterial activity was checked by agar well diffusion method. In this method a previously liquefied medium was inoculated with $0.1 \mathrm{~mL}$
Bacterial suspension having a uniform turbidity at temperature of $40^{\circ} \mathrm{C}$. In a sterile petri dish having an internal diameter of $8.5 \mathrm{~cm}$ was taken, $20 \mathrm{~mL}$ of culture medium was poured into it. Care was taken to form a uniform thickness of the medium in different plates. Wells were made aseptically with cork borer having $6 \mathrm{~mm}$ diameter after complete solidification of liquefied inoculated medium. In each of these plate extract, silver nanoparticle and topical gel formulation were placed carefully. Plates were kept for pre diffusion for $30 \mathrm{~min}$ at room temperature; then the plates were incubated at $37^{\circ} \mathrm{C}$ for $24 \mathrm{~h}$ and the zones of inhibition were measured.

\section{RESULTS AND DISCUSSION}

The first sign and symptom of acne is usually begins at the time of puberty. Acne is formed when the sebum, a lipid rich secretion of sebaceous glands come output on the surface of face and upper trunk through tiny hair follicle. This sebum has an important role in the pathogenesis of acne and it acts as a nutrient for the residual skin bacterium called Propionibacterium acnes. Sebum production is higher when compared to the unaffected individual and the severity of acne depends upon the amount of sebum production ${ }^{8}$. Based on the amount of sebum production and severity, acne is categorized into mild, moderate and severe condition.

Main drawback of the continuous therapeutic utilization of antimicrobial agents is the development of microbial resistance. In India, herbal medicines are used as holistic traditional systems of medicine due to its safety, cost effective and without any major side effects. Past two decades, the global trend is increased to utilize herbal medicines as complementary and alternative medicine. The art of medicine 
consists in amusing the patient while nature remedies cure the disease.

Generally for skin disease, antibiotics in the form of oral or topical formulation are used for the treatment. Topical formulation is preferred to produce the local and systemic effect.

\section{Evaluation of Extracts}

The color of the extracts was found to be dark green. The extracts are tested for its phytochemical analysis like alkaloids, carbohydrate, glycoside, saponins, phytosterols, phenol, tannin and flavonoids. The phytochemical analysis of the extract result is shown in (Table 1).

\section{Green Synthesis of AgNPs}

Green synthesis of AgNPs was prepared from plant extract. On mixing plant extract with the silver nitrate solution, a change in the solution color from pale yellow to dark brown was observed which indicates the reduction of silver ions and formation of silver nanoparticle. Formation of silver nanoparticle is shown in (Figure 1).

\section{Characterization of Silver Nanoparticles}

The UV absorption spectrum of Ocimum gratissimum has shown a peak specific in the range between 400 and $450 \mathrm{~nm}$. Peak specific in this region might be due to Mie scattering effect $^{24}$. The UV spectrum of silver nanoparticle is shown in (Figure 2).

Particle Size, Polydispersity Index and Zeta Potential

The particle size analysis was done by measuring the average particle size in the aqueous reaction mixture after the completion of reaction using the zeta sizer in dynamic light scattering mode. It was observed that the average particle size was 207.6 $\mathrm{nm}$ which confirmed that the silver ions were reduced into nanoparticles. The polydispersity index (PDI) of the silver nanoparticle was found to be 0.256 ; which indicates the broad distribution of globules and its homogencity. The zeta potential was determined by using Malvern zetasizer, it was found to be $-23.9 \mathrm{mV}$. The particle size and polydispersity index is shown in (Figure 3).

Physicochemical Evaluation of Gel Formulation

Among the various topical formulations, gel is preferred both in cosmetic and in pharmaceutical preparations due to its faster release rate of drug substances. Gel has various advantages because of its thixotropic property, greaseless, easily spreadable, easily removable, emollient, nonstaining and compatible with several excipients.

Physicochemical parameters such as homogenecity of color, presence of any foreign particle and fibers, washing ability, $\mathrm{pH}$ and viscosity are evaluated. Visual inspection results indicate that prepared topical gel formulation has uniform color distribution and free from any lumps, fibers and foreign particles. Formulation was easily washable and the $\mathrm{pH}$ was found to be 6.72 and 6.80 for gel prepared by Carbopol and HPMC as gel base which is near to the $\mathrm{pH}$ of the skin and hence is found to be compatible with skin. Viscosity was found to be $6406 \mathrm{cps}$ and $6642 \mathrm{cps}$ for gel prepared by Carbopol and HPMC as gel base. The observed results are comparable with the earlier literature ${ }^{22}$ and results are shown in (Table 2).

Spreadability

Bioavailability and therapeutic property of the topical formulation depends upon the spreadability. The spreadability is expressed of time in seconds based on the slip off from the gel by upper slide under certain load. Time taken 
for the separation of the two slides is less which indicates the topical formulation has better spreadability. The spreadability value was found to be $6.9 \pm 0.1(\mathrm{~g} . \mathrm{cm} / \mathrm{sec})$ and $7.1 \pm 0.1(\mathrm{~g} . \mathrm{cm} /$ $\mathrm{sec}$ ) for gel prepared by HPMC and Carbopol. The observed results were comparable with the earlier literature ${ }^{22}$.

\section{Antibacterial Activity of the Formulation}

The antibacterial activity study results of the formulated herbal gel showed antibacterial activity against acne causing bacteria such as Escherichia coli (E.coli), Staphylococcus aureus (S. aureus) and Propionibacterium acnes (P. acnes). The antibacterial study reveals that the silver nanoparticle of Ocimum gratissimum showed higher activity than the extract against all the pathogens. The antibacterial activity of the study results are shown in (Figures 4a-4c).

\section{CONCLUSION}

Concerning the environmental protection, green synthesis of nanoparticle has gained friendly and growing demand. Among the different metal nanoparticle, AgNPs has an excellent antibacterial agent due to its non-toxic effect on the human cells. Medicinal plants have been used as a home remedy from ancient time due to its variety of metabolites and its phytoconstituents. These phytoconstituents and metabolites can reduce the silver ions and assist synthesize of AgNPs from plant extracts. These AgNPs are having strong binding affinity with many functional groups of the plant extracts. The present study reveals a simple, rapid and economical method to synthesize AgNP silver nanoparticle from Ocimum gratissimum. The antibacterial activity is well demonstrated by agar well diffusion method. The synthesized AgNP silver nanoparticle using Ocimum gratissimum leaves extract showed higher activity than the extract. AgNP of Ocimum gratissimum in an aqueous gel base can be used as an appropriate formulation for the treatment of acne vulgaris.

\section{REFERENCES}

1. Pratik BM, Ashok GV, Pranita GA. A quest of Anti-acne Potential of Herbal Medicines for extermination of MDR Staphylococcus aureus. Int J Pharm Sci Invent. 2014;3(6):12-7.

2. Nguyen $\mathrm{R}, \mathrm{Su} J$. Treatment of acne vulgaris. Paediatrics and Child Health. 2011;21(3):119-25.

3. Sinha $\mathrm{P}$, Srivastava $\mathrm{S}$, Mishra $\mathrm{N}$, et al. New perspectives on antiacne plant drugs: contribution to modern therapeutics. BioMed Res Int. 2014:301-4.

4. Webster GF. Inflammation in acne vulgaris. J Am Acad Dermatol. 1995;33:247-53.

5. Bhalani U, Shah K. Preparation and evaluation of topical gel of Nigella sativa (kalonji). Int J Res Dev Pharm L Sci. 2015;4(4):1669-72.

6. Aruna MS, Sravani A, Resshma V. Formulation and evaluation of herbal acne gel. World J Pharm Res. 2015;4(5): 2324-30.

7. Bowe WP, Logan AC. Acne vulgaris, probiotics and the gut-brain-skin axis-back to the future? Gut Pathog. 2011;3(1):1-11.

8. Kuver S, Palshikar G. Formulation and evaluation of herbal antiacne face wash. International Journal of Phytotherapy Research. 2014;4(2):1-9.

9. Huh AJ, Kwon YJ. Nanoantibiotics: A new paradigm for treating infectious diseases using nanomaterials in the antibiotics resistant era. $\mathrm{J}$ Control Release. 2011;156(2):128-45.

10.Ray C. Acne and its treatment lines. Int J Pharm BioSci. 2013;3(1):1-16.

11. Verma S, Singh SP. Current and future status of herbal medicines. Vet World. 2008;1(11):347-50.

12.Jayashree A, Maneemegalai S. Studies on the antibacterial activity of the extracts from Tridax procumbens $L$ and Ixora coccinea $L$. Biomedicine. 2008;28(3):190-4.

13.Pal S, Tak YK, Song JM. Does the antibacterial activity of silver nanoparticles depend on the shape of the nanoparticle? A study of the Gramnegative bacterium Escherichia coli. Appl Environ Microbiol. 2007;73(6):1712-20.

14.Ashour AA, El-Gowelli DRHM, HEl-Kamel 
A. Green synthesis of silver nanoparticles using cranberry powder aqueous extract: Characterization and antimicrobial properties. Int J Nanomedicine. 2015;10:7207-21.

15.Nsofor CA, Chikezie UN, Azuwuike CO. Antibacterial activity of ocimum gratissimum leaves extract on Escherichia Coli O157. Palgo Journal of Medicine and Medical Science. 2014;1(2):15-8.

16. Nakamura CV, Nakamura TU, Bando E. Antibacterial activity of ocimum gratissimum L. essential oil. Mem Inst Oswaldo Cruz. 1999;94(5):675-78.

17.Mann A. Phytochemical constituents and antimicrobial and grain protectant activities of clove basil (Ocimum gratissimum L.) grown in Nigeria. Int J Plant Res. 2012;2(1):51-8.

18. Odey MO, Iwara IA, Udiba UU, et al. Preparation of plant extracts from indigenous medicinal plants. International Journal of Science and Technology. 2012;1(12):688-92.

19.Kokate CK, Purohit AP, Gokhale SB. Pharmacognosy, 47 $7^{\text {th }}$ Edn, Nirali Prakashan Publication, India. 2011.
20. Sumathy V, Jothy Lachumy S, Zuraini Z, et al. In vitro bioactivity and phytochemical screening of musa acuminata flower. Pharmacologyonline. 2011;2:118-27.

21.Nand P, Drabu S, Gupta RK, et al.In vitro and in vivo assessment of polyherbal topical gel formulation for the treatment of acne vulgaris. International Journal of Drug Delivery. 2012;4:434-42.

22. Yamini K, Onesimus T. Preparation and evaluation of herbal anti-acne gel. International Journal of Pharma and Bio Science. 2013;4(2):956-60.

23. Singh K, Panghal M, Kadyan S, et al. Evaluation of antimicrobial activity of synthesized silver nanoparticles using Phyllanthus amarus and Tinospora cordifolia medicinal plants. Journal of Nanomedicine and Nanotechnology. 2014;5(6):250.

24.Balouiri M, Sadiki M, Ibnsouda SK. Methods for in vitro evaluating antimicrobial activity: A review. Journal of Pharmaceutical Analysis. 2016;6:71-9. 
Table 1. Phytochemical screening of methanolic extract of Ocimum gratissimum

\begin{tabular}{|c|c|c|c|c|}
\hline S. No & Test & Procedure & Observation & Inference \\
\hline 1 & Alkaloids & $\begin{array}{c}\text { Extract }+ \text { Mayer's testExtract }+ \\
\text { Wagner's test } \\
\text { Extract }+ \text { Dragondroff's testExtract }+ \\
\text { Hager's test }\end{array}$ & $\begin{array}{l}\text { Yellow color ppt. } \\
\text { Brownish color ppt. } \\
\text { Red color ppt. } \\
\text { Yellow color ppt. }\end{array}$ & + \\
\hline 2 & Carbohydrate & $\begin{array}{c}\text { Extract }+ \text { Molish's testExtract }+ \\
\text { Benedicts test Extract }+ \text { Fehling's test }\end{array}$ & $\begin{array}{l}\text { Violet ring } \\
\text { Orange red color ppt. } \\
\text { Red color ppt. }\end{array}$ & - \\
\hline 3 & Glycoside & Extract + Modified borntrager's test & $\begin{array}{l}\text { No rose-pink color in the } \\
\text { Ammonical layer }\end{array}$ & - \\
\hline 4 & Saponins & Extract + Froth testExtract + Foam test & $\begin{array}{l}\text { Formation of foam. } \\
\text { Formation of foam and } \\
\text { persist for } 10 \mathrm{~min} .\end{array}$ & + \\
\hline 5 & Phytosterols & $\begin{array}{l}\text { Extract }+ \text { Salkowski's reagent } \\
\text { Extract }+ \text { Libermann burchard's } \\
\text { reagent }\end{array}$ & $\begin{array}{c}\text { Appearance of golden } \\
\text { yellow color } \\
\text { Formation of brown ring }\end{array}$ & - \\
\hline 6 & Phenols & Extract + Ferric chloride test & Bluish black color & + \\
\hline 7 & Tannins & Extract + Gelatin test & White ppt & + \\
\hline 8 & Flavonoids & Extract + lead acetate & Yellow color ppt & + \\
\hline
\end{tabular}

Table 2. Composition of the formulation

\begin{tabular}{|c|c|c|}
\hline S.No & Components Gel A & Components Gel B \\
\hline 1 & Carbopol $2 \mathrm{~g}$ & HPMC $2 \mathrm{~g}$ \\
\hline 2 & Glycerin $2 \mathrm{~g}$ & Glycerin $2 \mathrm{~g}$ \\
\hline 3 & Silver nanoparticle $0.02 \mathrm{~g}$ & Silver nanoparticle $0.02 \mathrm{~g}$ \\
\hline 4 & Water upto $100 \mathrm{~g}$ & Water upto $100 \mathrm{~g}$ \\
\hline
\end{tabular}




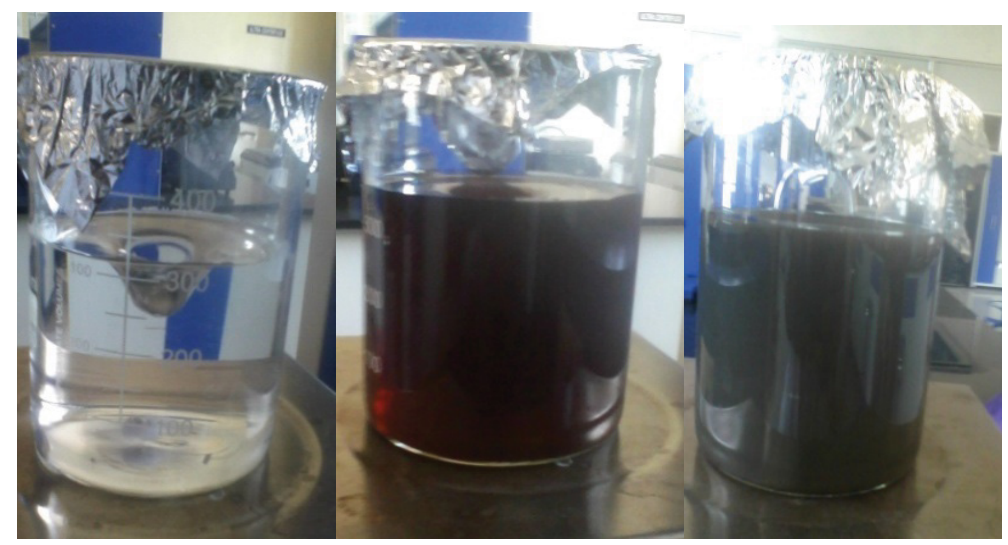

(a)

(b)

(c)
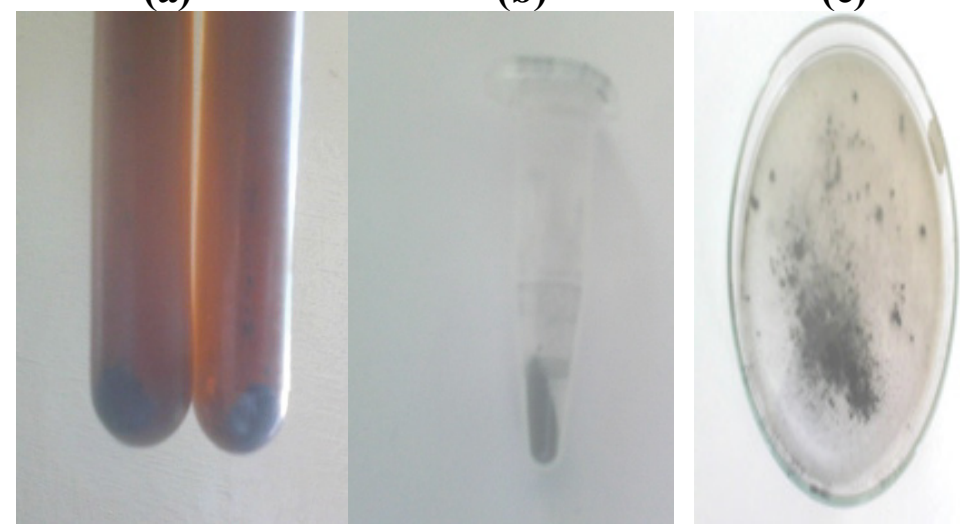

Note: (a) $\mathrm{AgNO}_{3}$ solution, (b) Reaction mixture (leaf extract+silver nitrate solution), (c) Reaction mixture at $60 \mathrm{~min}$, (d) Pellet formed by centrifugation, (e) Dried silver nanoparticles collected in eppendroff, (f) Dried silver nanoparticles

Figure 1. Formation of silver nanoparticle

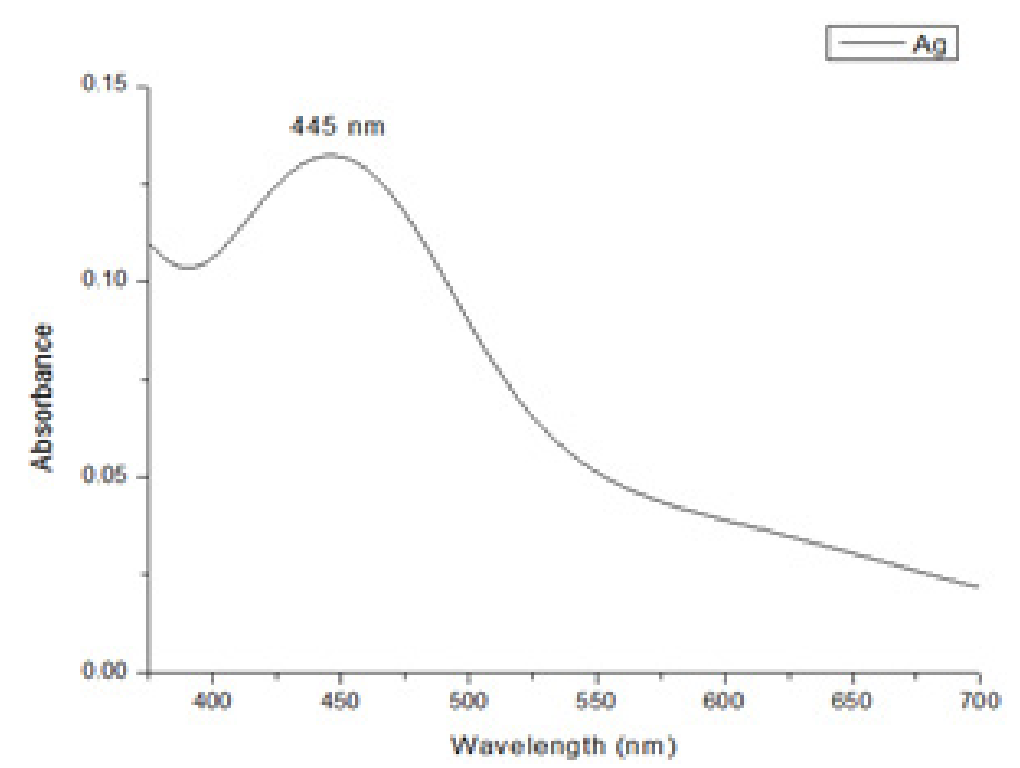

Figure 2. Absorption spectra of AgNPs of Ocimum gratissimum 


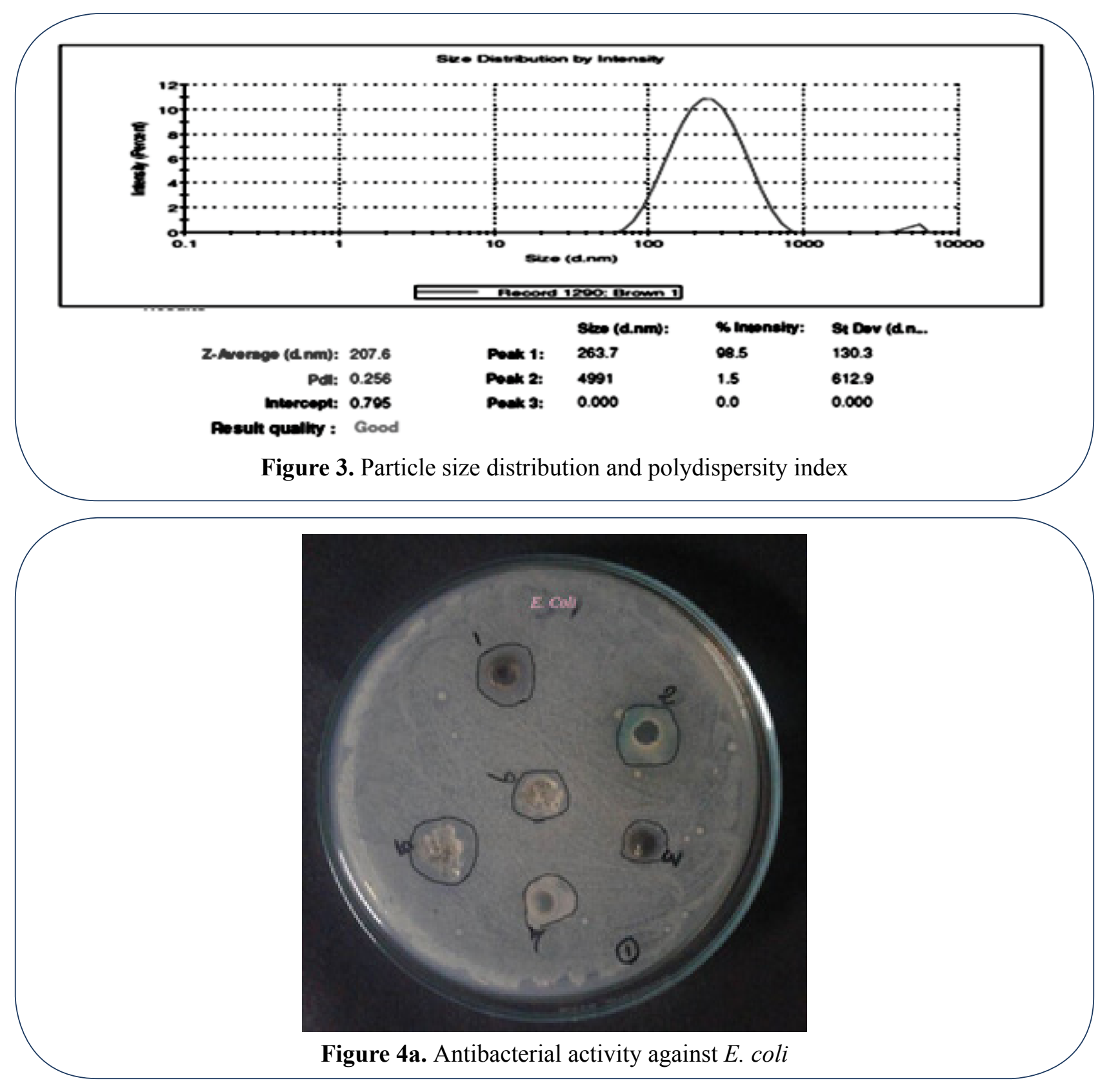




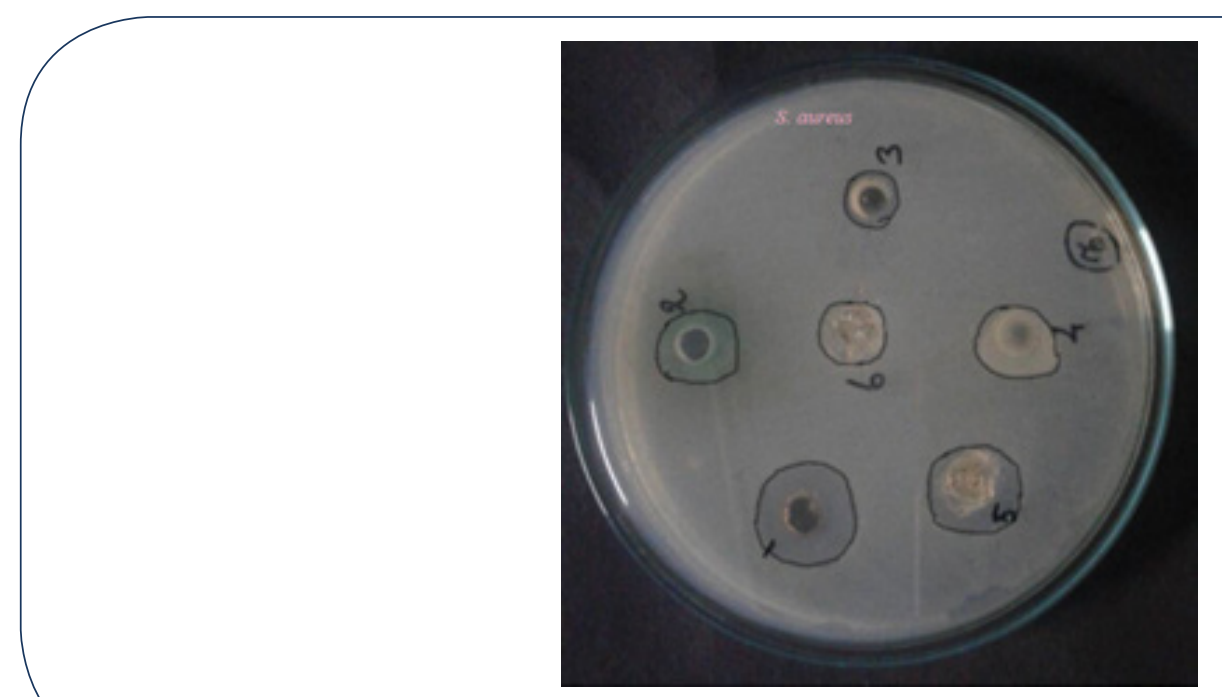

Figure 4b. Antibacterial activity against $S$. aureus

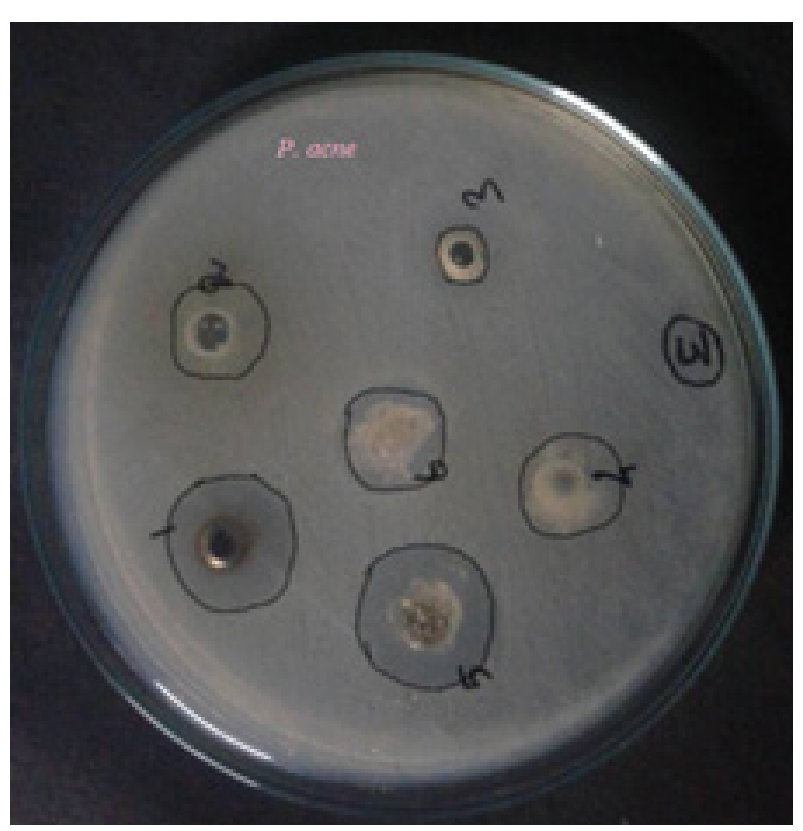

Figure 4c. Antibacterial activity against $\mathrm{P}$. acne

Note: 1) AgNPs solution, 2) Extract solution, 3) Extract in HPMC gel base, 4) AgNPs in HPMC gel base, 5) AgNPs in Carbopol gel base, 6) Extract in Carbopol gel base 